\title{
Long term biotransformation and toxicity of dimercaptosuccinic acid-coated magnetic nanoparticles support their use in biomedical applications
}

\author{
Raquel Mejías $^{\mathrm{a}}$, Lucía Gutiérrez ${ }^{\mathrm{b}}$, Gorka Salas ${ }^{\mathrm{b}, \mathrm{c}}$, Sonia Pérez-Yagüe ${ }^{\mathrm{a}}$, Teresa M. \\ Zotes $^{\mathrm{a}}$, Francisco J. Lázaro ${ }^{\mathrm{d}}$, María P. Morales ${ }^{\mathrm{b}}$, Domingo F. Barber,
}

${ }^{\mathrm{a}}$ Department of Immunology and Oncology, and NanoBiomedicine Initiative, Centro Nacional de Biotecnología (CNB)/CSIC, Darwin 3, Cantoblanco, 28049 Madrid, Spain

${ }^{\mathrm{b}}$ Department of Biomaterials and Bioinspired Materials, Instituto de Ciencia de Materiales de Madrid (ICMM)/CSIC, Sor Juana Inés de la Cruz 3, Cantoblanco, 28049 Madrid, Spain

'Nanomagnetism Group, Instituto Madrileño de Estudios Avanzados (IMDEA) Nanociencia, Faraday 9, Cantoblanco, 28049 Madrid, Spain

${ }^{\mathrm{d}}$ Department of Materials and Fluids Science and Technology, Universidad de Zaragoza, María de Luna 3, 50018 Zaragoza, Spain

*Corresponding author at: Department of Immunology and Oncology, and NanoBiomedicine Initiative, Centro Nacional de Biotecnología (CNB)/CSIC, Darwin 3, Cantoblanco, 28049 Madrid, Spain.

E-mail address: dfbarber@cnb.csic.es, Tel +34 91/585-5307, Fax +34 91/585-4506

\begin{abstract}
Although iron oxide magnetic nanoparticles (MNP) have been proposed for numerous biomedical applications, little is known about their biotransformation and long-term toxicity in the body. Dimercaptosuccinic acid (DMSA)-coated magnetic nanoparticles have been proven efficient for in vivo drug delivery, but these results must nonetheless be sustained by comprehensive studies of long-term distribution, degradation and toxicity. We studied DMSA-coated magnetic nanoparticles effects in vitro on NCTC 1469 nonparenchymal hepatocytes, and analyzed their biodistribution and biotransformation in vivo in C57BL/6 mice. Our results indicate that DMSA-coated magnetic nanoparticles have little effect on cell viability, oxidative stress, cell cycle or apoptosis on NCTC 1469 cells in vitro. In vivo distribution and transformation was studied by alternating current magnetic susceptibility measurements, a technique that permits distinction of MNP from other iron species. Our results show that DMSA-coated MNP accumulate in spleen, liver and lung tissues for extended periods of time, in which nanoparticles undergo a process of conversion from superparamagnetic iron oxide nanoparticles to other nonsuperparamagnetic iron forms, with no significant signs of toxicity.
\end{abstract}

KEYWORDS: Biotransformation, biocompatibility, biodistribution, cytotoxicity, nanoparticle, iron oxide

\section{Introduction}

Nanotechnology is currently an extremely active research area, and new applications are continually being developed for use as diagnostic and therapeutic agents [1]. Magnetic nanoparticles (MNP) are one of the most widely used nanotechnological tools in biomedicine; their nanometric size provides special features that favor the development of new applications, and they can be manipulated under the influence of an external magnetic field. In recent years, MNP have been proposed for applications such as magnetic 
resonance imaging (MRI), drug delivery, cell sorting, hyperthermia, nanosensors and tissue engineering $[2,3]$. The development of new technologies implies the need to determine their toxicity and to identify potential risks and side effects that could arise from their use, especially important in the case of nanotechnology [4].

The toxic potential of nanoparticles is due mainly to their small size. Nanomaterials have a high surface/volume ratio, rendering them very reactive, and allows their accumulation within cells or tissues $[5,6]$. This reactivity can lead to toxicity due to interaction between nanomaterials and biological components [7]. MNP toxicity also depends on other factors such as chemical composition, size, shape, surface coating, structure, porosity, solubility, surface charge, aggregation and oxidation [8-10]; this makes it difficult to draw general conclusions about their safety and biocompatibility. Previous studies analyzed in vitro toxicity of several kinds of iron oxide MNP on different cell types, with variable results. Whereas some showed that MNP can reduce cell viability, affect cell morphology or adhesion, or impair cell metabolism [6, 11-13], others found no significant cytotoxic effects [14-16]. These contradictory results are closely related to a concept known as "cell vision", refering to the contact point between nanoparticles and cells. Nanoparticles reach the plasma membrane of cells, which has a different composition depending on the cell type, and determine the "vision" that the cell has for these materials, and the effects that nanoparticles exert on the cell [17-20]. For this reason, it is necessary to analyze each nanoparticle type on an appropriate cell line. The results of in vitro toxicity tests are not sufficient, however, and must be validated in vivo. MNP biodistribution and toxicity in the body is the other main concern that arises from the increasingly widespread use of nanoparticles for biomedical applications. Several studies in animal models showed preferential accumulation of iron oxide MNP in spleen and liver, and to a lesser extent in other organs, depending on dosage and surface coating [21-25]. Other research showed that iron metabolism biochemical pathways can process iron oxide MNP [26, 27]. In addition to initial MNP accumulation, it is therefore important to analyze their temporal biodistribution and transformation, as variation in their location could determine changes in potential in vivo toxic effects. There is nonetheless little information available from long-term in vivo studies of these factors.

We undertook analysis of in vitro cytotoxicity and long-term in vivo biodistribution and toxicity of DMSA-MNP, whose efficiency for in vivo drug delivery has been demonstrated [23]. We analyzed the possible cytotoxic effects of DMSA-MNP on NCTC 1469 hepatic cells. As most previous studies of MNP cytotoxicity were conducted at low nanoparticle concentrations, or incubation times potentially too short to determine all possible toxic effects on cultured cells [28], we used iron concentrations up to $0.5 \mathrm{mg} / \mathrm{ml}$, and incubation times up to $72 \mathrm{~h}$.

The main cause of the toxic effects of MNP is excessive production of ROS (reactive oxygen species) [1], which can result in oxidative stress. As nanoparticle-induced oxidative stress can have several negative effects on cells, such as alteration of organelle structure, decreased cell viability, activation of various cell stress pathways, cell cycle impairment or apoptosis induction [29], we studied these processes in a variety of in vitro tests. To determine DMSA-MNP biodistribution in vivo, we used alternating current (AC) susceptibility measurements, a method utilized to characterize the magnetic properties of MNP and to detect them in tissues [30-32]. We present the analysis of DMSA-MNP accumulation and biotransformation in various organs for three months after a multipledose treatment in C57BL/6 mice. We also studied DMSA-MNP elimination in feces and 
MNP toxicity by biochemical analysis of blood and urine. Our results help to determine the risks involved in the biomedical use of this type of MNP.

\section{Materials and Methods}

\subsection{Synthesis and characterization of magnetic nanoparticles}

DMSA-MNP were synthesized as described [33] with slight modifications. Briefly, a mixture of $\mathrm{Fe}(\mathrm{acac})_{3}(20 \mathrm{mmol}), 1,2$-dodecanediol $(100 \mathrm{mmol})$, oleic acid $(60 \mathrm{mmol})$ and oleylamine $(60 \mathrm{mmol})$ in 1-octadecene $(200 \mathrm{ml})$ was introduced in a four-necked flask and heated $\left(200^{\circ} \mathrm{C}, 2 \mathrm{~h}\right)$ with mechanical stirring under $\mathrm{N}_{2}$ flow. The solution was heated to reflux $\left(315^{\circ} \mathrm{C}, 30 \mathrm{~min}\right)$, cooled to room temperature (RT) and washed several times with ethanol using a permanent magnet to precipitate the particles and discard the supernatant. Nanoparticles were dispersed in toluene, and $80 \mathrm{ml}$ of this suspension, containing $1.8 \mathrm{mmol}$ $\mathrm{Fe}$, were added to a solution of DMSA $(2 \mathrm{mmol})$ in dimethyl sulfoxide $(20 \mathrm{ml})$. The mixture was stirred mechanically for $48 \mathrm{~h}$. Solvent was discarded, precipitated DMSAMNP were washed three times with ethanol and redispersed in water. Finally, $\mathrm{pH}$ was increased to 10 by adding a $\mathrm{NaOH}$ solution, and the resulting homogeneous dispersion was dialyzed and filtered through a $0.22 \mu \mathrm{m}$ pore-size filter before adjusting to $\mathrm{pH} 7$. Iron concentration of the dispersion was measured by inductively coupled plasma atomic emission spectroscopy (ICP-AES). Transmission electron microscopy (TEM) was performed using a 200-KeV JEOL-2000 FXII microscope. MNP size, shape and distribution were analyzed from TEM images. A drop of a dilute magnetic nanoparticle suspension was placed on a carbon-coated copper grid and the solvent allowed to evaporate at room temperature. Colloidal characterization was performed by dynamic light scattering (DLS) using a ZetaSizer Nano ZS (Malvern).

\subsection{Cell culture}

The murine NCTC 1469 non-parenchymal hepatocyte cell line was cultured in DMEM with $10 \%$ horse serum, $100 \mathrm{IU} / \mathrm{ml}$ penicillin, $100 \mu \mathrm{g} / \mathrm{ml}$ streptomycin and $2 \mathrm{mM}$ L-glutamine in standard culture conditions $\left(37^{\circ} \mathrm{C}, 5 \% \mathrm{CO}_{2}, 90 \%\right.$ relative humidity).

\subsection{Nanoparticle uptake}

For iron uptake and subcellular localization of nanoparticles, cells were preincubated with DMSA-MNP $(0.5 \mathrm{mg} \mathrm{Fe} / \mathrm{ml})$ for $24 \mathrm{~h}$. Cells were then fixed in $2 \%$ glutaraldehyde and $1 \%$ tannic acid in HEPES ( $2 \mathrm{~h}, \mathrm{RT})$. Cells were rinsed with HEPES, post-fixed with $1 \%$ osmium tetroxide $(1 \mathrm{~h})$ and $2 \%$ uranyl acetate $\left(30 \mathrm{~min}\right.$; both at $\left.4^{\circ} \mathrm{C}\right)$, dehydrated with a series of acetone solutions and gradually infiltrated with Epon resin. The resin was allowed to polymerize $\left(60^{\circ} \mathrm{C}, 48 \mathrm{~h}\right)$, and ultrathin sections $(60-70 \mathrm{~nm})$ were obtained with a diamond knife mounted on a Leica EM UC6 ultramicrotome. Sections were supported on a formvar/carbon-coated gold grid and observed using a JEOL-1011 electron microscope (acceleration voltage $100 \mathrm{kV}$ ). Images were obtained with an Erlangshen ES1000W camera.

\subsection{Cell viability assay}

Cell viability was determined by the AlamarBlue assay (Invitrogen). Cells were cultured in 24-well plates $\left(10^{4}\right.$ cells/well; $1 \mathrm{ml}$ complete medium) with various concentrations of DMSA-MNP or $100 \mu \mathrm{M}$ bisphenol A (BPA) in dimethyl sulfoxide (DMSO). AlamarBlue reagent was added to each well $(100 \mu \mathrm{l})$, and incubated $(72 \mathrm{~h})$. Fluorescence was evaluated at different times in a TECAN Infinite 200 Pro fluorometer $(560 \mathrm{~nm}$ excitation wavelength, $590 \mathrm{~nm}$ emission wavelength). Cell viability was expressed as the percentage of fluorescence of DMSA-MNP-treated or BPA-treated cells compared to untreated cells. 


\subsection{Oxidative stress analysis}

Oxidative stress can be determined indirectly by analyzing reduced glutathione (GSH) levels using the GSH-sensitive probe monochlorobimane (mCB). Cells were preincubated with various concentrations of DMSA-MNP $(24 \mathrm{~h})$ or $750 \mu \mathrm{M} \mathrm{H}_{2} \mathrm{O}_{2}(30 \mathrm{~min})$. As mCB can be incorporated to other -SH protein groups, we added controls treated with $200 \mu \mathrm{M}$ 1-buthionine-(S,R)-sulfoximine (BSO) for $24 \mathrm{~h}$. This treatment depletes cell GSH levels, and the appropriate BSO-treated control background signal was subtracted from each sample. For the last hour of incubation, $100 \mu \mathrm{M} \mathrm{mCB}$ was added to each sample. Fluorescence was analyzed immediately on a TECAN Infinite 200 Pro fluorometer $(390 \mathrm{~nm}$ excitation wavelength, $485 \mathrm{~nm}$ emission wavelength).

2.6 Caspase-3 activity assay

Apoptosis of NCTC 1469 cells was determined by analysis of cleaved caspase-3 activity after incubation with various DMSA-MNP concentrations, $100 \mu \mathrm{M}$ BPA in DMSO, or DMSO alone $(72 \mathrm{~h})$. Assays were performed using a fluorometric caspase-3 assay kit (Abcam), following manufacturer's instructions.

\subsection{Western blot}

NCTC 1469 cells, preincubated with various DMSA-MNP concentrations, $750 \mu \mathrm{M}$ $\mathrm{H}_{2} \mathrm{O}_{2}$, DMSO, or $100 \mu \mathrm{M}$ BPA in DMSO for different time, were lysed in lysis buffer ( $1 \%$ Triton-X 100, $50 \mathrm{mM}$ Tris, $150 \mathrm{mM} \mathrm{NaCl}, 5 \mathrm{mM} \mathrm{NaF}, 1 \mathrm{mM}$ sodium orthovanadate, $1 \mathrm{mM}$ PMSF, $1 \mathrm{mM}$ EDTA, $1 \mu \mathrm{g} / \mathrm{ml}$ aprotinin, $1 \mu \mathrm{g} / \mathrm{ml}$ leupeptin, $2 \mathrm{nM}$ okadaic acid)(30 min, $\left.4^{\circ} \mathrm{C}\right)$. The lysate was clarified by centrifugation and $40 \mu \mathrm{g}$ of total protein from each sample, determined with the Micro BCA protein assay kit (Pierce), were mixed with Laemmli sample buffer $(250 \mathrm{mM}$ Tris- $\mathrm{HCl} \mathrm{pH} 6.8,10 \%$ SDS, 30\% glycerol, 5\% $\beta$ mercaptoethanol, $0.02 \%$ bromophenol blue) and loaded on $12 \%$ SDS-polyacrylamide gels for electrophoresis. Proteins were transferred to a $0.2 \mu \mathrm{m}$-pore nitrocellulose membrane (BioRad), which was blocked with $5 \% \mathrm{w} / \mathrm{v}$ bovine serum albumin in Tris-buffered saline (TBS). For immunoblotting, we used specific primary antibodies for phospho-ERK, ERK, phospho-JNK (Thr183/Tyr185), JNK, phospho-p38 MAPK (Thr180/Tyr182), p38 MAPK, cleaved caspase-3 (all from Cell Signaling) and $\beta$-actin (Sigma). After incubation with appropriate horseradish peroxidase-conjugated secondary antibodies (Dako), protein bands were visualized using ECL Western Detection Reagent (GE Healthcare) and developed on A-Plus Medical film (Konica Minolta).

\subsection{Cell cycle analysis}

For cell cycle analysis, cells were incubated with various DMSA-MNP concentrations or $100 \mu \mathrm{M}$ BPA $(72 \mathrm{~h})$. Cells were collected by centrifugation, resuspended and incubated in ice-cold $70 \%$ ethanol $(5 \mathrm{~min}$ ), washed with ice-cold PBS and stained with $20 \mu \mathrm{g} / \mathrm{ml}$ propidium iodide and $100 \mu \mathrm{g} / \mathrm{ml}$ ribonuclease (45 min, RT). A total of $10^{4}$ cells were analyzed per experiment. The percentage of cells in each cell cycle phase was determined in a GALLIOS flow cytometer (Beckman Coulter) using MultiCycle AV software (Phoenix Flow Systems).

\subsection{Mouse model}

Twelve-week-old female C57BL/6 mice (Harlan Laboratories) were maintained in the Centro Nacional de Biotecnología (CNB) animal facility. Mice $(n=4 /$ group $)$ received 5 intravenous (i.v.) injections of phosphate-buffered saline (PBS; control) or DMSA-MNP (15 mg Fe/kg/injection) in two weeks. At several times after the last injection, feces and

urine samples were collected, mice were euthanized and spleen, liver, lungs, kidneys and 
blood were harvested for analysis. All animal studies were approved by the CNB Ethics Committee for Animal Experimentation in compliance with national and European Union legislation.

\subsection{Alternating current (AC) magnetic susceptibility measurements}

Murine tissues were freeze-dried overnight and transferred to gelatin capsule sample holders for magnetic characterization using a Quantum Design MPMS-XL SQUID magnetometer, with $\mathrm{AC}$ amplitude of $0.25 \mathrm{mT}$ in a temperature range from 5 to $200 \mathrm{~K}$ at 1 $\mathrm{Hz}$.

\subsection{Prussian blue staining}

After extraction, organs were fixed in 4\% paraformaldehyde and embedded in paraffin blocks. Sections $(7 \mu \mathrm{m})$ were deparaffinized and rehydrated before staining. Prussian blue staining was performed using equal volumes of $1 \mathrm{~N} \mathrm{HCl}$ and $10 \% \mathrm{w} / \mathrm{v}$ potassium ferrocyanide (15 min) and counterstained with filtered Mayer's hematoxylin (3 min) and eosin $(30 \mathrm{sec})$. Sections were washed in running tap water $(10 \mathrm{~min})$, dehydrated and mounted with Entellan (Merck).

\subsection{Iron quantification in feces}

Quantitative determination of iron was carried out by ICP-AES analysis. Feces were collected and pooled at different times after DMSA-MNP administration. Samples were incubated with $65 \%$ nitric acid $\left(1 \mathrm{ml}, 1 \mathrm{~h}, 60^{\circ} \mathrm{C}\right)$ and analyzed. The elemental analysis determined the total iron content in samples.

\subsection{Blood and urine biochemical analysis}

Blood samples were maintained at room temperature $(4 \mathrm{~h})$, centrifuged (100 x g, $30 \mathrm{~min})$ and sera collected. An independent laboratory analyzed serum samples for alanine aminotransferase (ALT), aspartate aminotransferase (AST), creatinine, and $\gamma$ glutamyltranspeptidase (GGT). Urine samples were analyzed for glucose, protein, bilirubin, urobilinogen, $\mathrm{pH}$ and blood using AUTION Sticks 10EA for urine (Arkray).

\subsection{Quantification and statistical analysis}

Gel bands were quantified with ImageJ software (NIH). Data are represented as mean \pm SD. Statistical analysis was performed using a two-tailed Student's $t$ test. Data were considered significantly different at a value of $p<0.05$ and highly significant at $p<0.01$.

\section{Results and discussion}

\subsection{Nanoparticle synthesis and characterization}

Using established synthesis protocols [33, 34], we obtained uniform monodisperse DMSA-MNP with a magnetite core of $9.2 \mathrm{~nm} \pm 13 \%$ (Fig. 1A). Some aggregation took place when particles were transferred to water, yielding DMSA-MNP suspensions with hydrodynamic sizes of $\sim 65 \mathrm{~nm}$ (Fig. 1B). The polydispersity index (PDI) was 0.22 . We also analyzed nanoparticle $\zeta$-potential in a wide $\mathrm{pH}$ range (Fig. 1C); these studies are of interest as data indicate that particle size and surface charge can influence cell internalization and biodistribution of MNP [7, 16]. However, nanoparticle physicochemical properties in a physiological medium may vary, due to protein adsorption to nanoparticle surface forming the so-called protein corona, which can influence nanoparticle stability, uptake, and toxicity $[35,36]$. We analyzed the MNP hydrodynamic size in complete culture medium, and size variations at different time points up to $72 \mathrm{~h}$ (Fig. 1D). The long-term MNP incubation in this medium resulted in an increase in the hydrodynamic size to $\sim 170 \mathrm{~nm}$, which subsequently decreased during the first 5 hours of incubation to $\sim 85 \mathrm{~nm}$, that remained 
stable thereafter, probably due to the initial adsoprtion of a large amount of low-affinity proteins, which are then replaced by a smaller number of proteins with higher affinity [35]. This type of MNP has been used in previous in vitro studies, on several cell lines, showing MNP uptake and accumulation in lysosomes [16, 23]. These organelles contain an acid medium. Low $\mathrm{pH}$ may affect MNP and protein corona surface charge, which could result in variations in MNP aggregation state. Therefore, we analyzed the hydrodynamic size in complete medium at acidic $\mathrm{pH}$ (Fig. 1E). The size reached in this case was similar to that obtained for the nanoparticles in complete medium at physiological $\mathrm{pH}$. However, unlike what was observed at physiological $\mathrm{pH}$, in this case the hydrodynamic size did not decrease over time, but remained around $150 \mathrm{~nm}$, indicating nanoparticle aggregation due to decreased stability of the colloidal suspension.

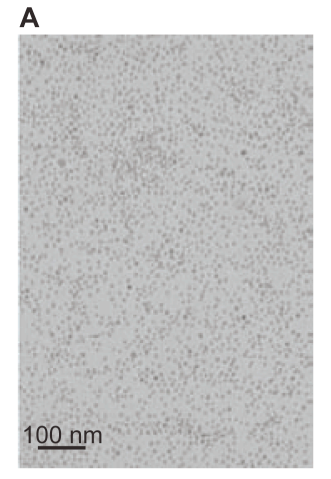

D

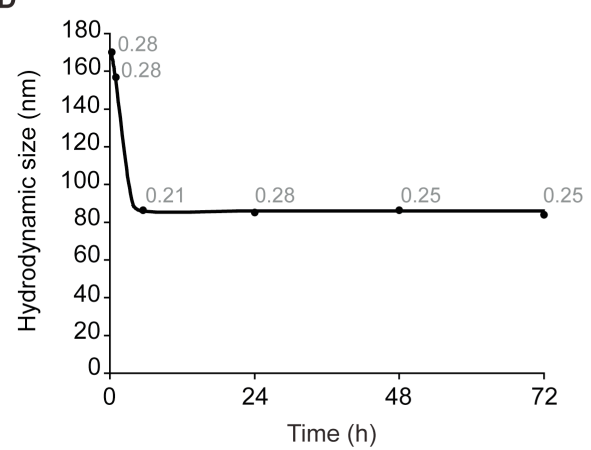

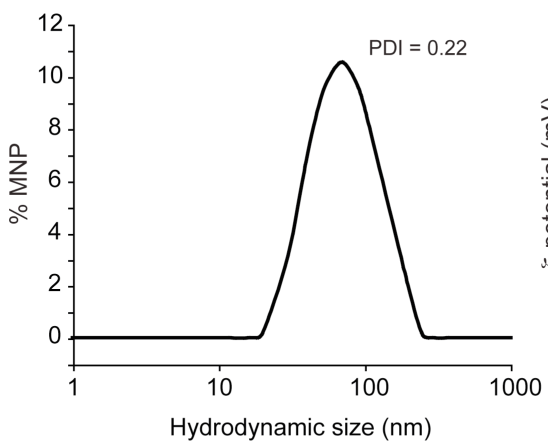

C

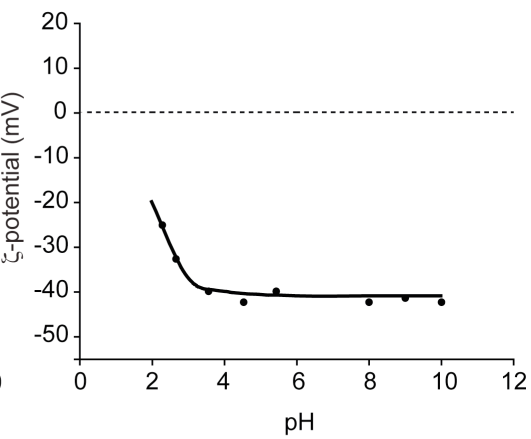

$E$

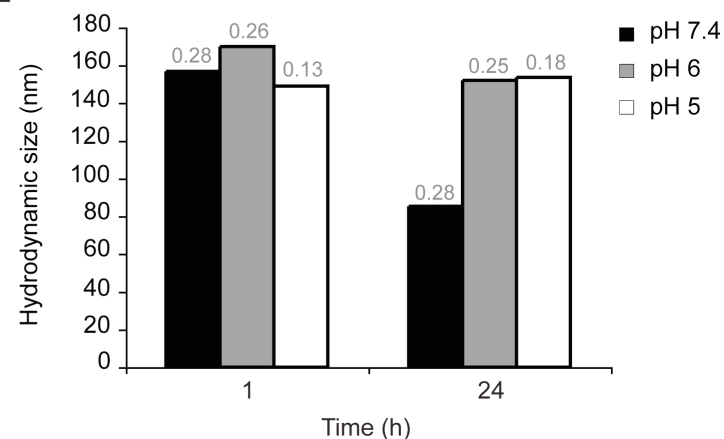

Fig. 1. Nanoparticle characterization. (A) Transmission electron micrograph (TEM) of DMSA-MNP. (B) Hydrodynamic diameter of DMSA-MNP determined by dynamic light scattering (DLS). PDI = polydispersity indez. (C) Surface charge of DMSA-MNP at various $\mathrm{pH}$, determined by DLS. (D) Hydrodynamic diameter of DMSA-MNP in complete culture medium at various incubation times determined by DLS. Data are represented as mean hydrodynamic size. The numbers in each time point indicate the PDI. (E) Hydrodynamic diameter of DMSA-MNP in complete culture medium at various $\mathrm{pH}$ and two incubation times determined by DLS. Data are represented as mea hydrodynamic size, and the numbers indicate the PDI.

\subsection{NCTC 1469 cell uptake of DMSA-MNP}

Although MNP can affect cell viability even when they are not internalized, most of their effects are uptake-dependent and the nature of the effect depends largely on MNP fate within the cell [7, 37]; it is thus necessary to determine whether nanoparticles are internalized. We analyzed DMSA-MNP internalization by TEM after $24 \mathrm{~h}$ incubation. TEM images showed that DMSA-MNP entered NCTC 1469 cells and accumulated in large double-membrane vesicles distributed in cytoplasm (Fig. 2A). Although nanoparticleinduced oxidative stress can result in damage to organelles [38], we observed no changes in 
organelle structure, possibly because MNP remained inside closed vesicles, which could prevent toxic effects on cell components.
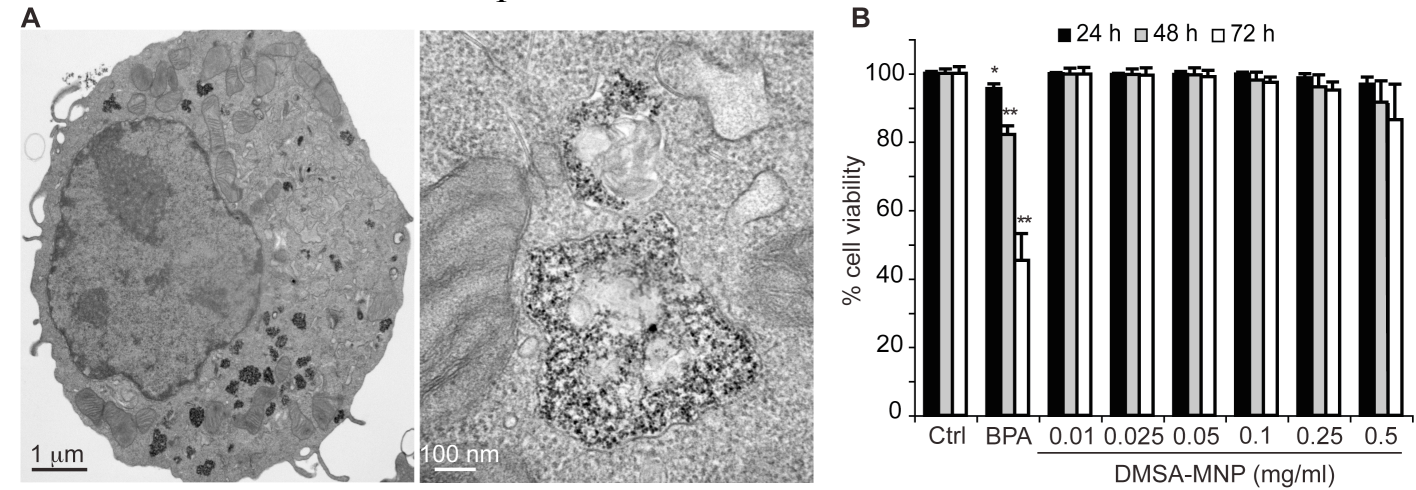

Fig. 2. Nanoparticle uptake and cell viability. (A) Representative TEM of NCTC 1469 cells incubated with $0.5 \mathrm{mg} / \mathrm{ml} \mathrm{Fe}$ $(24 \mathrm{~h})$. (B) AlamarBlue viability assay of NCTC 1469 cells untreated (Ctrl), incubated with various DMSA-MNP concentrations or $100 \mu \mathrm{M}$ BPA $(24,48$ or $72 \mathrm{~h})$. Data were normalized to control cells, and are shown as mean $\pm \operatorname{SD}(n=$ 3). Two-tailed, unpaired Student's $t$ test, ${ }^{*} \mathrm{p}<0.05 ; * * \mathrm{p}<0.01$.

\subsection{In vitro DMSA-MNP cytotoxicity}

Most in vitro toxicity assays are based on the use of colorimetric or fluorescent dyes to determine cell viability or function. Although these assays are accepted as general toxicity detection methods, they might not be completely accurate when testing nanomaterials, due to nanoparticle-dye interaction or adsorption, nanoparticle color or autofluorescence [39]. Nanoparticle toxicity must thus be assessed using specific tests. Here we analyzed cell viability, oxidative stress, activation of cell stress pathways, apoptosis and cell cycle to determine DMSA-MNP toxicity on NCTC 1469 cells.

Several previous studies examined the effects of DMSA-MNP on different cell types, and showed little reduction in cell viability [11, 16, 40]. These studies used low MNP doses, however, or incubation times too short to permit analysis of all possible toxic effects of iron oxide nanoparticles. Here we used higher concentrations and longer incubation times than usual. We analyzed cell viability using the AlamarBlue assay (Fig. 2B). Cultured NCTC 1469 cell viability was slightly affected by DMSA-MNP at all incubation times and nanoparticle concentrations tested, whereas exposure of these cells to $100 \mu \mathrm{M}$ BPA, used as a liver toxicity control [41], produced a significant decrease in cell viability. These data showed that DMSA-MNP have little toxicity in this cell line, with no notable influence on cell proliferation.

MNP can produce oxidative stress from excessive generation of ROS that exceeds the antioxidant capacity of cells. GSH is an antioxidant defense able to neutralize ROS at low levels, generating the oxidized form GSSG. When the GSH/GSSG ratio decreases, cells activate cell stress responses, which can be protective, inflammatory, or lead to cell death [42]. We tested oxidative stress indirectly by GSH detection in NCTC 1469 cells. GSH has a critical role in cell defense against oxidizing agents [43], acting as a reducing equivalent $\left(\mathrm{H}^{+}+\mathrm{e}^{-}\right)$donor. Low GSH levels are associated with oxidative stress, for which they are a good marker [44]. One method used to determine GSH levels in living cells is based on the GSH-sensitive probe mCB. Glutathione S-transferases form GSH-mCB complexes that can be measured fluorometrically [45]. Treatment with various concentrations of DMSA-MNP led to a non-significant decrease in GSH levels, whereas $750 \mu \mathrm{M} \mathrm{H}_{2} \mathrm{O}_{2}$ treatment reduced GSH to $28 \%$ of control levels (Fig. 3A). 
Cell responses depend on the activation of various signaling pathways. Three such pathways, ERK (extracellular signal-regulated kinase), p38 MAPK (mitogen-activated protein kinase) and JNK (c-Jun N-terminal kinase) MAPK cascades, have been studied as upstream oxidative stress events after cell exposure to nanoparticles [38, 46]. Nanoparticle binding to some cell surface receptors can activate these pathways; depending on the specific pathway activated, as well as stimulus strength and duration [38], apoptosis mediators such as caspases can be activated, or changes induced in cell proliferation. The ERK pathway is involved in proliferation, differentiation, development, cell survival and tumorigenesis. JNK activation is critical for regulating stress responses and is involved in apoptosis, inflammation and tumorigenesis; p38, which is activated by many physical and chemical cell stressors, regulates cell motility, inflammation, osmoregulation and apoptosis [47]. In Western blot, we analyzed the phosphorylated and unphosphorylated forms of ERK, p38 and JNK in NCTC 1469 cells after $24 \mathrm{~h}$ treatment with several DMSA-MNP concentrations or 30 min treatment with $750 \mu \mathrm{M} \mathrm{H}_{2} \mathrm{O}_{2}$. DMSA-MNP treatment did not alter expression either of unphosphorylated forms of the three proteins, or of phosphorylated forms of JNK and p38 at any time point (Fig. 3B). ERK phosphorylation increased after $0.5 \mathrm{mg} / \mathrm{ml}$ DMSA-MNP treatment $(24 \mathrm{~h})$, although the phosphorylated protein/total protein ratio was not significantly higher compared to controls (Fig. 3C). We detected increased ERK, p38 and JNK phosphorylation when cells were incubated with $\mathrm{H}_{2} \mathrm{O}_{2}$ (Fig. 3B,C), indicating pathway activation, which correlated with reduced GSH levels (Fig. 3A). 

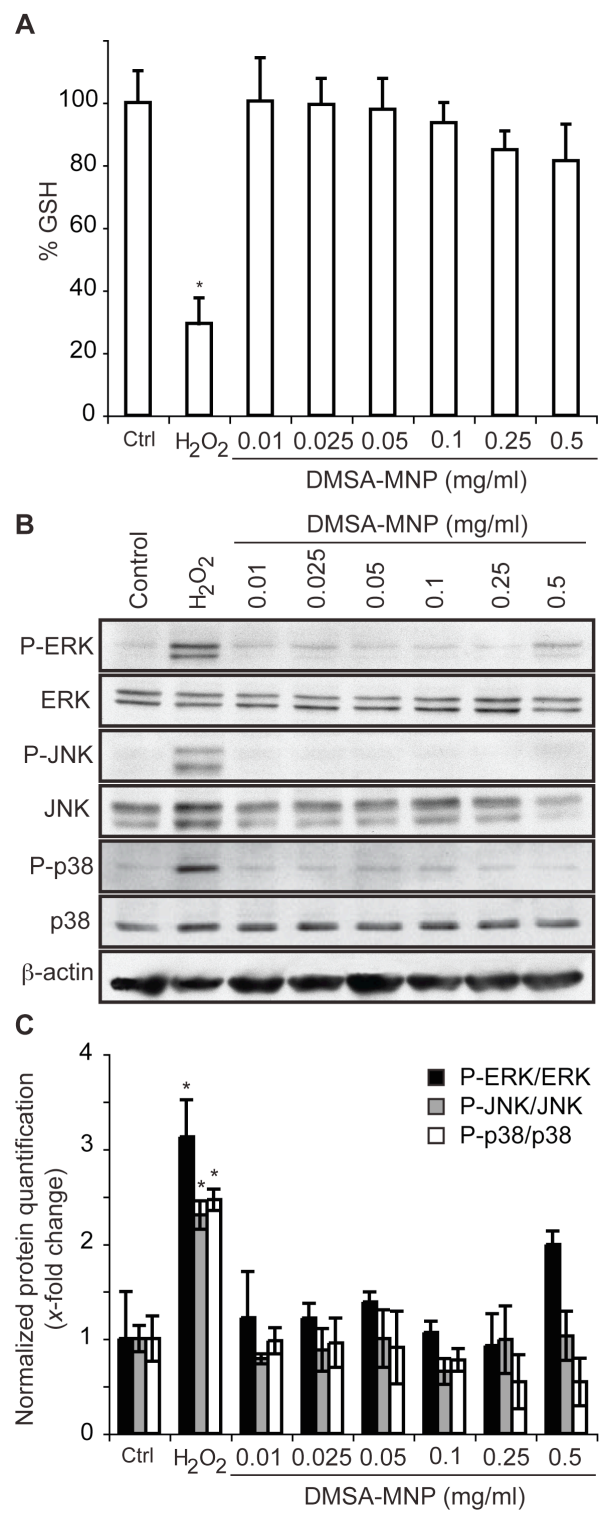

Fig. 3. Oxidative stress analysis. (A) Glutathione (GSH) content in NCTC 1469 cells untreated (Ctrl), incubated with various DMA-MNP concentrations $(24 \mathrm{~h})$ or $750 \mu \mathrm{M} \mathrm{H}_{2} \mathrm{O}_{2}(30 \mathrm{~min})$. Data were normalized to control cells $(n=3)$. (B) Representative images of western blot analysis of stress signaling pathway activation in NCTC 1469 cells untreated (control), incubated with DMA-MNP or $\mathrm{H}_{2} \mathrm{O}_{2}$ as in (A). Phosphorylated and total ERK, JNK and p38 were detected as stress indexes; $\beta$-actin was used as a loading control. (C) Amounts of phosphorylated and total ERK, JNK and p38 were normalized to that of $\beta$-actin, represented as $x$-fold change in the phosphorylated/total protein ratio relative to untreated controls (Ctrl). Data shown as mean $\pm \mathrm{SD}(n=3)$. Two-tailed, unpaired Student's $t$ test, ${ }^{*} \mathrm{p}<0.05$.

Nanoparticle interaction with the cell surface or intracellular MNP accumulation might activate other cell responses such as programmed cell death. Apoptosis is produced by the activation of caspases, effector proteases involved in proteolytic cascades that lead to cell death; these cascades are classified as mitochondrial-dependent or -independent. Both routes converge in the activation of caspase-3 [48]. We used two methods to analyze caspase-3 activation in NCTC 1469 cells exposed to DMSA-MNP. Apoptotic activity was determined using a caspase-3 activity assay. Cells cultured with DMSA-MNP did not show increased caspase- 3 activity relative to untreated controls, while $100 \mu \mathrm{M}$ BPA treatment increased protease activity $>4.5$ times (Fig. 4A). We also used immunoblot analysis of 
cleaved caspase-3. Active caspase-3 was not detectable in samples from cells incubated with DMSA-MNP, whereas it was found when cells were treated with $100 \mu \mathrm{M}$ BPA (Fig. 4B). Quantification of the protein bands normalized to untreated controls showed results similar to those from the caspase-3 activity assay (Fig. 4C).

A

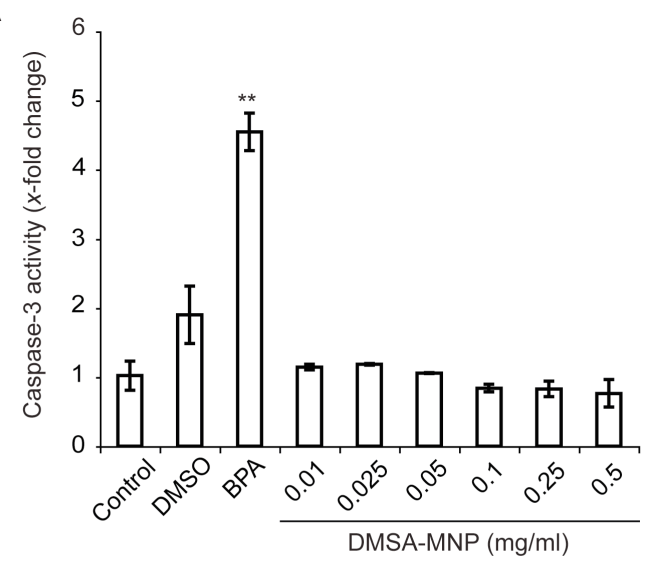

B

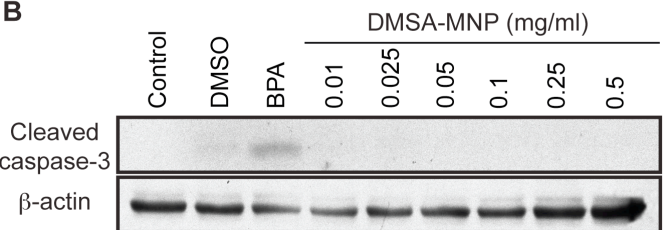

C

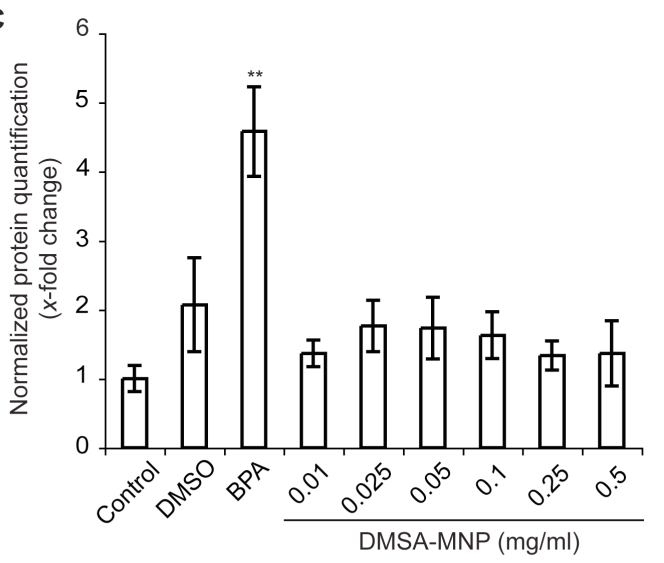

D

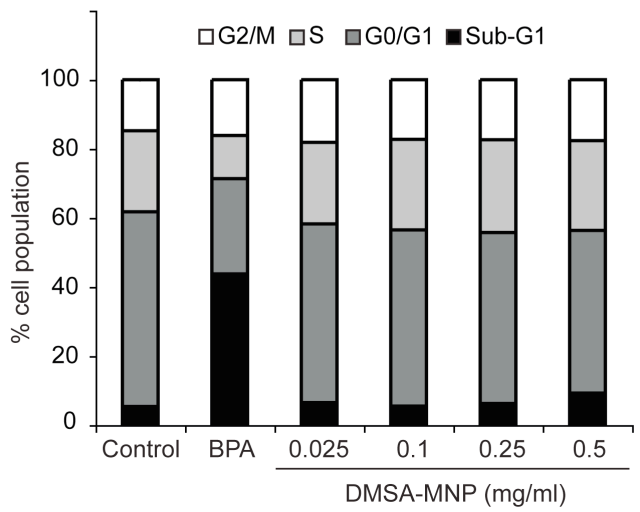

Fig. 4. Apoptosis and cell cycle analysis. (A) Caspase-3 activity assay of NCTC 1469 cells untreated (control), incubated with various DMSA-MNP concentrations, $100 \mu \mathrm{M}$ BPA in dimethyl sulfoxide (DMSO), or DMSO alone (72 h). Data were normalized and represented as $x$-fold change relative to untreated controls $(n=3)$. (B) Representative images of western blot analysis of cleaved caspase- 3 and $\beta$-actin as apoptotic index and loading control, respectively. (C) The 
cleaved caspase- 3 amount was normalized to that of $\beta$-actin and represented as $x$-fold change relative to untreated controls $(n=3)$. (D) Representative cell cycle cytometric analysis of NCTC 1469 cells untreated (control), incubated with various DMSA-MNP concentrations, or $100 \mu \mathrm{M}$ BPA $\left(72 \mathrm{~h} ; 10^{4}\right.$ cells/experiment; $\left.n=2\right)$. Data are shown as mean \pm SD. Twotailed, unpaired Student's $t$ test, $* * \mathrm{p}<0.01$.

Nanoparticles also affect cell cycle progression [5, 6], which is closely related to cell uptake of MNP [49]. Cytometric analysis of the cell cycle showed that $100 \mu \mathrm{M}$ BPA led to an increase in the sub-G1 population $(>40 \%)$ and a decrease in G0-G1 $(\sim 30 \%)$ and $\mathrm{S}$ $(\sim 10 \%)$ populations compared to untreated controls (Fig. 4D). DMSA-MNP slightly affected the NCTC 1469 cell cycle after $72 \mathrm{~h}$ treatment, with a maximum $6.8 \%$ increase in the sub-G1 population at $0.5 \mathrm{mg} / \mathrm{ml}$ (Fig. 4D).

\subsection{Biodistribution and biotransformation of DMSA-MNP in murine tissues}

To study DMSA-MNP in murine tissues after multiple dose i.v. administration, we used AC magnetic susceptibility measurements. The out-of-phase susceptibility $\left(\chi \chi^{\prime \prime}(T)\right)$ profile is especially useful for detecting superparamagnetic material in tissue samples, since other iron-containing species such as paramagnetic deoxyhemoglobin or diamagnetic oxyhemoglobin do not contribute to $\chi$ "(T). Moreover, MNP can be distinguished from other superparamagnetic biogenic species such as ferritin, based on differences in the temperature position of their $\chi$ "(T) maxima [50, 51].

The magnetic behavior of DMSA-MNP has been characterized [32]. Before degradation, the magnetic susceptibility of DMSA-MNP shows a single peak in both in- and out-ofphase components, indicative of blocking of particle magnetic moments. In samples at a distinct particle concentration, susceptibility peak location on the temperature axis changes due to variations in dipolar interactions produced by the distinct MNP aggregation levels. The $\chi$ '(T) peak is located at $\sim 65 \mathrm{~K}$ for the most aggregated samples, and at $\sim 40 \mathrm{~K}$ for the most dilute, in which dipolar interactions are negligible [32]. In addition to changes in the degree of MNP aggregation, particle size change is another source of variation in shape and location of the MNP $\chi$ "(T) peak at different temperature, such that a size reduction shifts the $\chi$ "(T) maximum towards temperatures lower than $40 \mathrm{~K}$ for the type of DMSA-MNP used here [32].

In our experiments, blood, spleen, liver, kidney, heart and lung tissues were magnetically characterized to track MNP accumulation and degradation for 3 months postnanoparticle administration. We found minimal or no $\chi$ "(T) signal in blood, heart and kidney tissues (not shown), whereas the $\chi$ "(T) component of the magnetic susceptibility of all spleen, liver and lung tissues showed a single peak in the temperature range observed for similar DMSA-MNP in earlier studies [32], confirming the presence of MNP in the tissues; controls (PBS-treated mice) showed no peak (Fig. 5A). The highest $\chi$ "(T) signal, found in spleen and liver samples, was one order of magnitude greater than that for lung. Over the 3-month period after nanoparticle administration, the maximum $\chi$ "(T) for each tissue decreased systematically. The $\chi$ "(T) peak also shifted towards lower temperatures with time, clearly observed when $\chi$ "(T) data are normalized to the maximum (Fig. 5B). The results indicate a degradation process over the 3-month period, possibly due to nanoparticle disaggregation, reduction in nanoparticle size, or both. The position of the $\chi$ "(T) peak on the temperature axis for liver samples at 3 months post-DMSA-MNP administration was $\sim 30 \mathrm{~K}$. As this temperature is lower than the that of the $\chi$ "(T) peak for diluted DMSA-MNP samples in conditions of negligible dipolar interactions [32], this displacement cannot be 
explained only by disaggregation; nanoparticle size appears to be altered, alone or accompanied by nanoparticle disaggregation. In spleen and lung tissues, the $\chi$ " $(\mathrm{T})$ peak at the lowest temperature is $\sim 40 \mathrm{~K}$, rendering it rather difficult to estimate the fractions of the total number of particles that suffered disaggregation or particle size reduction.
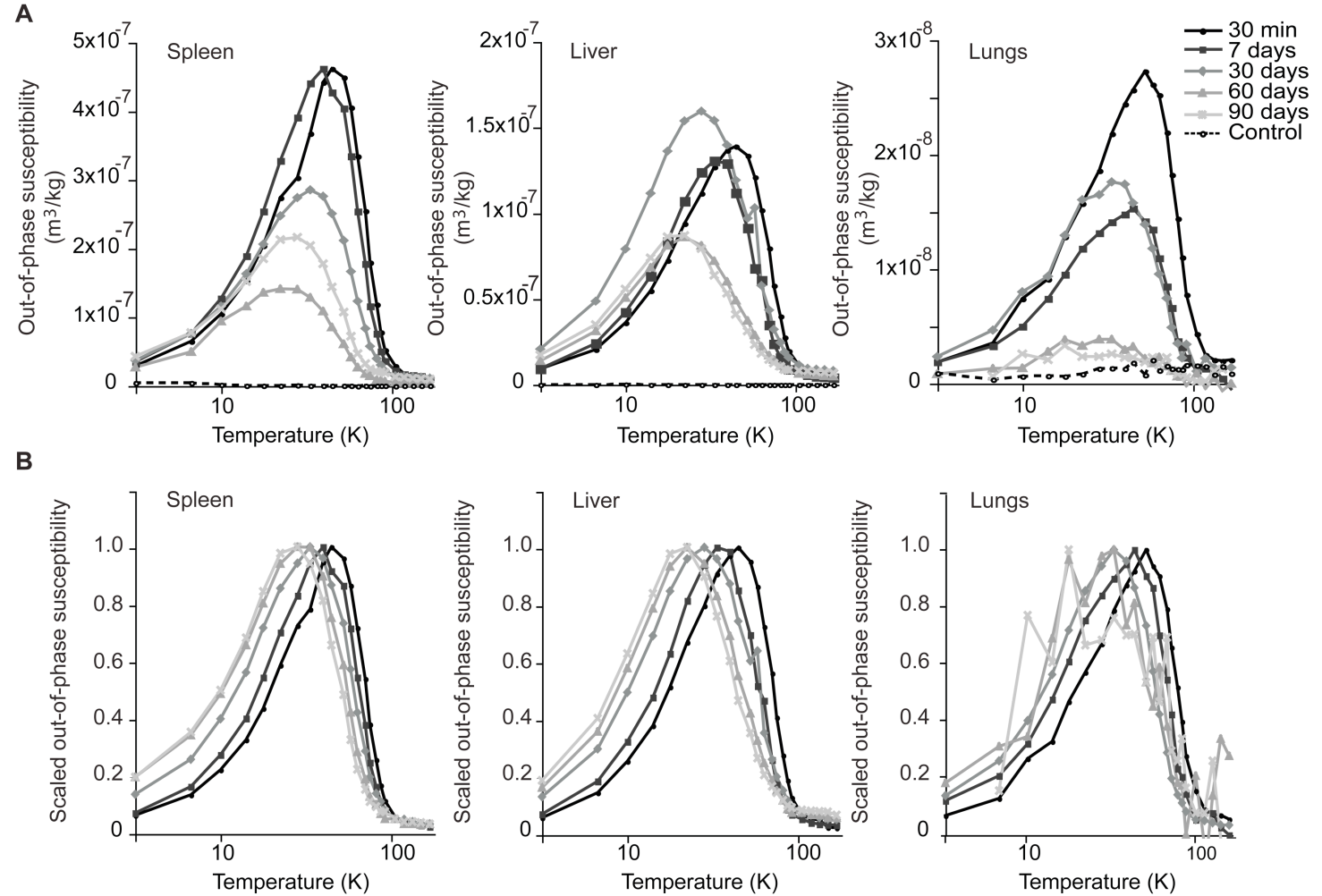

Fig. 5. Temperature dependence of the out-of-phase component of the AC magnetic susceptibility of murine tissues from phosphate-buffered saline (PBS)- (control) or DMSA-MNP-treated mice at different times post-administration (A) as obtained from the SQUID magnetometer, and (B) scaled to their maxima.

The height of the $\chi$ "(T) peak, when plotted per mass of sample, is proportional to particle quantity in tissue [32]. At short times post-injection, as nanoparticles have not yet begun to degrade, MNP dispersions in agar can be used as calibration standards to quantify particle quantity in tissues $[32,51]$. In this study, as aggregation and particle size change over time, we have no appropriate standards for precise magnetic quantification. Qualitative information can nonetheless be obtained from the relative height of the $\chi$ "(T) peak at different time points. We observed a clear trend in liver, lung and spleen samples, as peak height tended to decrease with time after DMSA-MNP administration. At 3 months post-particle administration, we found approximately half the nanoparticle quantity observed immediately after administration. The spleen showed three times fewer nanoparticles at 3 months post-administration compared to week one after MNP injection. The greatest reduction was found in lungs, in which nanoparticle quantities decreased approximately six fold.

AC magnetic susceptibility results were complemented with Prussian blue staining of lung, liver and spleen sections, which showed iron agglomeration from 30 min to 3 months after i.v. administration of DMSA-MNP (Fig. 6). Lung and liver showed a reduction in number of iron clumps, but liver sections also showed an increase in the size of iron deposits over time, which might be explained by the formation of phagocytic cell clusters 
in the liver parenchyma [52]. Spleen sections showed stained areas in the red pulp, even in control tissues, possibly due to storage of iron degradation products as a result of erythrocyte phagocytosis and the presence of metallophilic macrophages [53]. Although the superparamagnetic signal observed by AC susceptibility measurement diminished over time in spleen, this decrease was not clearly visible in Prussian blue-stained spleen sections. This implies that MNP were transformed to other non-superparamagnetic iron forms that can be processed and partially removed by iron metabolic pathways. In contrast to results from studies in which other DMSA-coated nanoparticles were used [25], we observed no DMSA-MNP in kidney, which might be due to differences in the animal model and/or physical characteristics of the nanoparticles. In addition, biodistribution might depend not only on the physicochemical properties of this type of nanoparticle, but also on extrinsic factors such as MNP dose and the type of anesthetic used [54]. Apart from this iron accumulation, we found no structural or histopathological changes in any of the tissues.

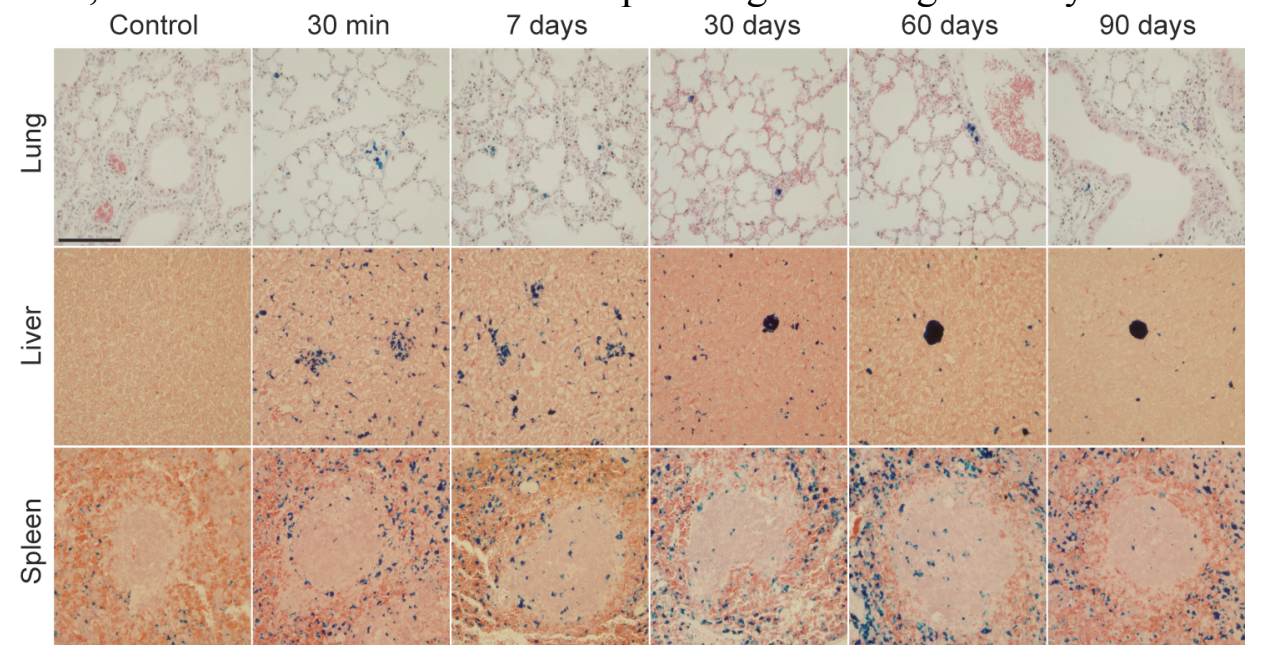

Fig. 6. Prussian blue staining of tissue sections from PBS- (control) or DMSA-MNP-treated mice at different times postadministration. Representative images of 15 tissue sections. Bar: $100 \mu \mathrm{m}$.

\subsection{MNP elimination}

Although there are some previous studies of in vivo MNP distribution and clearance [21, $52,55,56]$, little is known of the route of nanoparticle elimination. Very small amounts of iron are typically lost from normal hepatocytes. In iron overload situations, however, bile can be an important iron excretory pathway [57]. To determine whether this was the case after DMSA-MNP administration and accumulation in liver tissue, we analyzed feces iron content by ICP-AES for a 3-month period post-DMSA-MNP injection, and found increased iron content in feces from day 7 to day 30 (Fig. 7A). We also analyzed feces samples with high iron content by AC magnetic susceptibility measurements, and found no superparamagnetic signal related to the presence of MNP (not shown). This is consistent with the MNP transformation observed in tissues, in which superparamagnetic material is biotransformed to other iron forms and can thus be eliminated. 

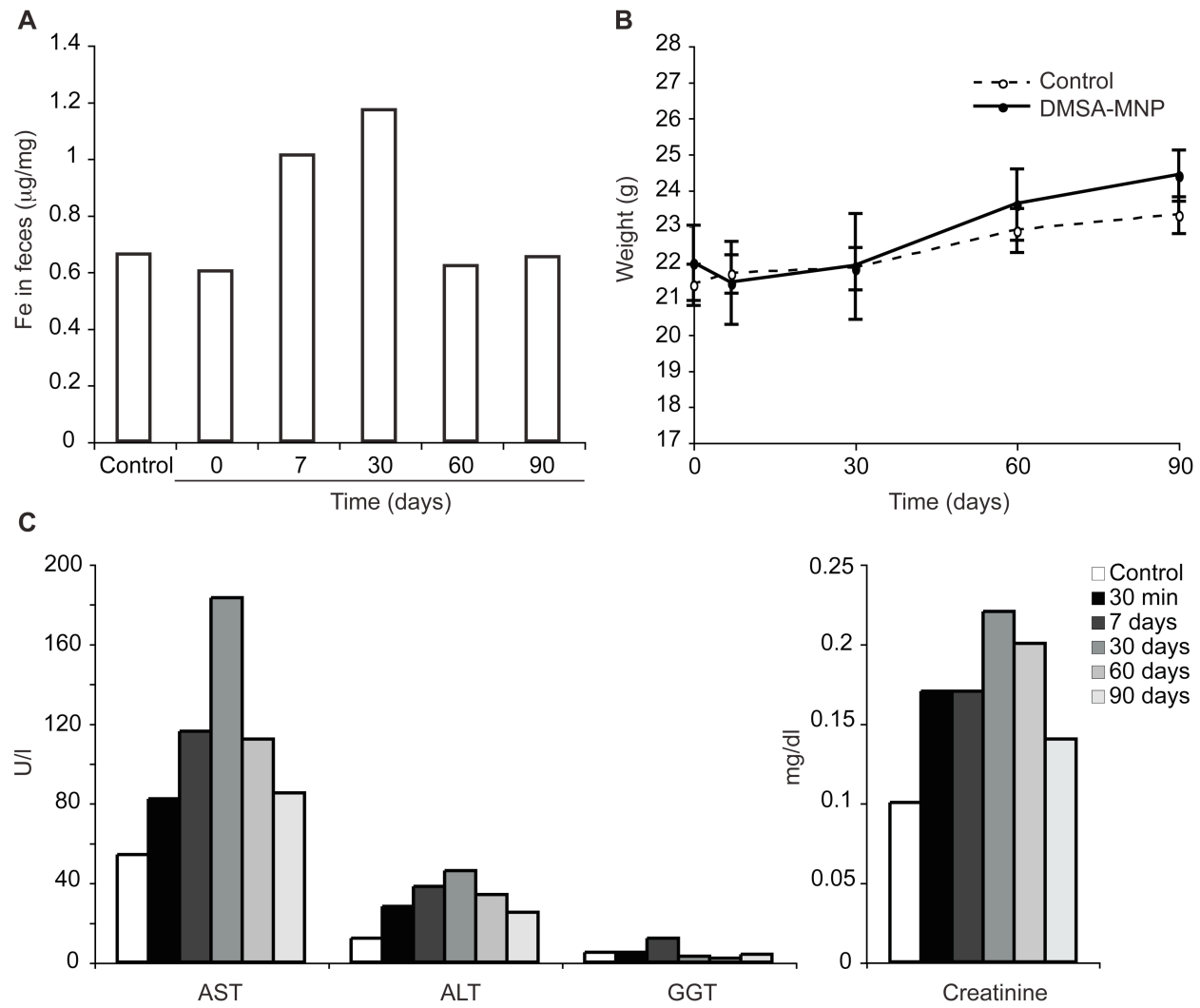

Fig. 7. Excretion and in vivo toxicity of DMSA-MNP. (A) ICP-AES analysis of iron content in pooled feces from PBS(control) or DMSA-MNP-treated mice at different times post-administration. (B) Body weights of PBS- (control) or DMSA-MNP-treated mice were monitored over a 3-month period after treatment. Data are shown as mean $\pm \operatorname{SD}(n=4)$. (C) Biochemistry of blood samples collected from one mouse each from the PBS- (control) or DMSA-MNP-treated groups at different times post-administration. Serum concentrations of aspartate aminotransferase (AST), alanine aminotransferase (ALT), $\gamma$-glutamyltranspeptidase (GGT) and creatinine were analyzed.

\subsection{In vivo toxic effects of DMSA-MNP}

One of the main needs for these in vivo studies is to test for possible toxic effects resulting from nanoparticle administration, whether due to initial accumulation or to subsequent biotransformation processes. Mouse body weight, monitored over a 3-month period after DMSA-MNP administration, showed no obvious changes (Fig. 7B). Macroscopic and histopathological examination of all tissues harvested at several times after the final injection yielded no signs of tissue damage (see Fig. 6).

As we observed increased quantities of MNP in liver and spleen at 3 months after the last DMSA-MNP injection, we tested serum and urine for signs of in vivo toxicity. Analysis of serum from DMSA-MNP-injected mice compared to controls showed transient increases in aspartate aminotransferase (AST) and alanine aminotransferase (ALT), enzymes associated mainly with hepatic damage, with a peak at 1 month post-treatment. We found transient increases in $\gamma$-glutamyltranspeptidase (GGT) and creatinine levels 7 days after the last DMSA-MNP injection (Fig. 7C). These increases did not compromise mouse survival, and the levels detected were within the range of normal values for female C57BL/6 mice, considering age and the blood extraction method [58, 59]. Biochemical analysis of urine showed normal results at all times for all parameters analyzed (Table 1). 
Table 1. Urine biochemical analysis results for PBS- (control) and DMSA-MNP-treated mice

Time post-DMSA-MNP administration (days)

\begin{tabular}{l|cccccc} 
& Control & $\mathbf{0}$ & $\mathbf{7}$ & $\mathbf{3 0}$ & $\mathbf{6 0}$ & $\mathbf{9 0}$ \\
\hline Glucose & - & - & - & - & - & - \\
Protein & \pm & \pm & \pm & \pm & \pm & \pm \\
Bilirubin & - & - & - & - & - & - \\
Urobilinogen & - & - & - & - & - & - \\
pH & 6 & 6 & $5-6$ & 6 & $5-6$ & 6 \\
Blood & - & - & - & - & - & -
\end{tabular}

Notes: Analysis performed using reactive test strips for urine $(n=4)$.

Symbols: -, negative;, $\pm 15 \mathrm{mg} / \mathrm{dl}$.

\section{Conclusions}

We studied DMSA-MNP biocompatibility in vitro, and long-term biodistribution and clearance in vivo. At the concentrations studied (up to $0.5 \mathrm{mg} / \mathrm{ml}$ ), the particles produced no significant effects on viability, oxidative stress, apoptosis or cell cycle of NCTC 1469 murine non-parenchymal hepatocytes. The in vivo analyses indicate continuous biotransformation of MNP in liver and spleen. Although some signs of acute toxicity were found one month post-administration, these were transient and did not compromise mouse survival. The results confirm the promise of DMSA-MNP for clinical use.

\section{Acknowledgements}

We thank C Mark for editorial assistance. RM holds a post-doctoral contract supported by EU-FP7 MULTIFUN project ( $n^{\circ}$ 262943), LG holds a Sara Borrell post-doctoral contract (CD09/00030) from the Carlos III Health Institute, Spanish Ministry for Health, Social Services and Equality (MSSSI), and TMZ received a FPU pre-doctoral fellowship from the Spanish Ministry of Economy and Competitiveness (MINECO). This work was partially supported by grants from the MINECO (SAF-2011-23639 to DFB and MAT2011-23641 and CSD2007-00010 to MPM), the Research Network in Inflammation and Rheumatic Diseases (RIER) of the ISCIII-MSSSI Cooperative Research Thematic Network program (RD08/0075/0015 to DFB), the Madrid regional government (S009/MAT-1726 to MPM), and EU-FP7 MULTIFUN project (no. 262943).

\section{References}

[1] V.I. Shubayev, T.R. Pisanic, 2nd, S. Jin, Magnetic nanoparticles for theragnostics, Adv Drug Deliv Rev, 61 (2009) 467-477.

[2] M. Colombo, S. Carregal-Romero, M.F. Casula, L. Gutierrez, M.P. Morales, I.B. Bohm, J.T. Heverhagen, D. Prosperi, W.J. Parak, Biological applications of magnetic nanoparticles, Chem Soc Rev, 41 (2012) 4306-4334.

[3] P. Tartaj, M.P. Morales, T. Gonzalez-Carreno, S. Veintemillas-Verdaguer, C.J. Serna, The iron oxides strike back: from biomedical applications to energy storage devices and photoelectrochemical water splitting, Adv Mater, 23 (2011) 5243-5249. 
[4] A. Kroll, M.H. Pillukat, D. Hahn, J. Schnekenburger, Current in vitro methods in nanoparticle risk assessment: limitations and challenges, Eur J Pharm Biopharm, 72 (2009) 370-377.

[5] N. Singh, G.J. Jenkins, R. Asadi, S.H. Doak, Potential toxicity of superparamagnetic iron oxide nanoparticles (SPION), Nano Rev, 1 (2010) 5358.

[6] S.J. Soenen, U. Himmelreich, N. Nuytten, M. De Cuyper, Cytotoxic effects of iron oxide nanoparticles and implications for safety in cell labelling, Biomaterials, 32 (2011) 195-205.

[7] A.E. Nel, L. Madler, D. Velegol, T. Xia, E.M. Hoek, P. Somasundaran, F. Klaessig, V. Castranova, M. Thompson, Understanding biophysicochemical interactions at the nano-bio interface, Nat Mater, 8 (2009) 543-557.

[8] S. Arora, J.M. Rajwade, K.M. Paknikar, Nanotoxicology and in vitro studies: the need of the hour, Toxicol Appl Pharmacol, 258 (2012) 151-165.

[9] N. Lewinski, V. Colvin, R. Drezek, Cytotoxicity of nanoparticles, Small, 4 (2008) 2649.

[10] S.A. Love, M.A. Maurer-Jones, J.W. Thompson, Y.S. Lin, C.L. Haynes, Assessing nanoparticle toxicity, Annu Rev Anal Chem (Palo Alto Calif), 5 (2012) 181-205.

[11] M. Auffan, L. Decome, J. Rose, T. Orsiere, M. De Meo, V. Briois, C. Chaneac, L. Olivi, J.L. Berge-Lefranc, A. Botta, M.R. Wiesner, J.Y. Bottero, In vitro interactions between DMSA-coated maghemite nanoparticles and human fibroblasts: A physicochemical and cyto-genotoxical study, Environ Sci Technol, 40 (2006) 4367-4373.

[12] W. Kai, X. Xiaojun, P. Ximing, H. Zhenqing, Z. Qiqing, Cytotoxic effects and the mechanism of three types of magnetic nanoparticles on human hepatoma BEL-7402 cells, Nanoscale Res Lett, 6 (2011) 480.

[13] T.R. Pisanic, 2nd, J.D. Blackwell, V.I. Shubayev, R.R. Finones, S. Jin, Nanotoxicity of iron oxide nanoparticle internalization in growing neurons, Biomaterials, 28 (2007) 25722581.

[14] E.R. de Freitas, P.R. Soares, P. Santos Rde, R.L. dos Santos, J.R. da Silva, E.P. Porfirio, S.N. Bao, E.C. Lima, P.C. Morais, L.A. Guillo, In vitro biological activities of anionic gamma-Fe2O3 nanoparticles on human melanoma cells, J Nanosci Nanotechnol, 8 (2008) 2385-2391.

[15] Y. Liu, Z. Chen, J. Wang, Systematic evaluation of biocompatibility of magnetic Fe3O4 nanoparticles with six different mammalian cell lines, J Nanopart Res, 13 (2011) 199-212.

[16] A. Villanueva, M. Canete, A.G. Roca, M. Calero, S. Veintemillas-Verdaguer, C.J. Serna, P. Morales Mdel, R. Miranda, The influence of surface functionalization on the enhanced internalization of magnetic nanoparticles in cancer cells, Nanotechnology, 20 (2009) 115103.

[17] S. Laurent, C. Burtea, C. Thirifays, U.O. Hafeli, M. Mahmoudi, Crucial ignored parameters on nanotoxicology: the importance of toxicity assay modifications and "cell vision", PLoS One, 7 (2012) e29997.

[18] M. Mahmoudi, S. Laurent, M.A. Shokrgozar, M. Hosseinkhani, Toxicity evaluations of superparamagnetic iron oxide nanoparticles: cell "vision" versus physicochemical properties of nanoparticles, ACS Nano, 5 (2011) 7263-7276.

[19] M. Mahmoudi, S.N. Saeedi-Eslami, M.A. Shokrgozar, K. Azadmanesh, M. Hassanlou, H.R. Kalhor, C. Burtea, B. Rothen-Rutishauser, S. Laurent, S. Sheibani, H. Vali, Cell 
"vision": complementary factor of protein corona in nanotoxicology, Nanoscale, 4 (2012) 5461-5468.

[20] J. Rauch, W. Kolch, M. Mahmoudi, Cell type-specific activation of AKT and ERK signaling pathways by small negatively-charged magnetic nanoparticles, Sci Rep, 2 (2012) 868.

[21] T.K. Jain, M.K. Reddy, M.A. Morales, D.L. Leslie-Pelecky, V. Labhasetwar, Biodistribution, clearance, and biocompatibility of iron oxide magnetic nanoparticles in rats, Mol Pharm, 5 (2008) 316-327.

[22] M.G. Krukemeyer, V. Krenn, M. Jakobs, W. Wagner, Mitoxantrone-iron oxide biodistribution in blood, tumor, spleen, and liver--magnetic nanoparticles in cancer treatment, J Surg Res, 175 (2012) 35-43.

[23] R. Mejias, S. Perez-Yague, L. Gutierrez, L.I. Cabrera, R. Spada, P. Acedo, C.J. Serna, F.J. Lazaro, A. Villanueva, P. Morales Mdel, D.F. Barber, Dimercaptosuccinic acid-coated magnetite nanoparticles for magnetically guided in vivo delivery of interferon gamma for cancer immunotherapy, Biomaterials, 32 (2011) 2938-2952.

[24] R. Mejias, S. Perez-Yague, A.G. Roca, N. Perez, A. Villanueva, M. Canete, S. Manes, J. Ruiz-Cabello, M. Benito, A. Labarta, X. Batlle, S. Veintemillas-Verdaguer, M.P. Morales, D.F. Barber, C.J. Serna, Liver and brain imaging through dimercaptosuccinic acid-coated iron oxide nanoparticles, Nanomedicine (Lond), 5 (2010) 397-408.

[25] V. Monge-Fuentes, M.P. Garcia, M.C. Tavares, C.R. Valois, E.C. Lima, D.S. Teixeira, P.C. Morais, C. Tomaz, R.B. Azevedo, Biodistribution and biocompatibility of DMSAstabilized maghemite magnetic nanoparticles in nonhuman primates (Cebus spp.), Nanomedicine (Lond), 6 (2011) 1529-1544.

[26] L. Gutierrez, F.J. Lazaro, A.R. Abadia, M.S. Romero, C. Quintana, M. Puerto Morales, C. Patino, R. Arranz, Bioinorganic transformations of liver iron deposits observed by tissue magnetic characterisation in a rat model, J Inorg Biochem, 100 (2006) 1790-1799. [27] E.K. Schlachter, H.R. Widmer, A. Bregy, T. Lonnfors-Weitzel, I. Vajtai, N. Corazza, V.J. Bernau, T. Weitzel, P. Mordasini, J. Slotboom, G. Herrmann, S. Bogni, H. Hofmann, M. Frenz, M. Reinert, Metabolic pathway and distribution of superparamagnetic iron oxide nanoparticles: in vivo study, Int J Nanomedicine, 6 (2011) 1793-1800.

[28] S. Naqvi, M. Samim, M. Abdin, F.J. Ahmed, A. Maitra, C. Prashant, A.K. Dinda, Concentration-dependent toxicity of iron oxide nanoparticles mediated by increased oxidative stress, Int J Nanomedicine, 5 (2010) 983-989.

[29] G. Liu, J. Gao, H. Ai, X. Chen, Applications and Potential Toxicity of Magnetic Iron Oxide Nanoparticles, Small, 9 (2012) 1533-1545.

[30] A.D. Arelaro, A.L. Brandl, E. Lima, L.F. Gamarra, G.E.S. Brito, W.M. Pontuschka, G.F. Goya, Interparticle interactions and surface contribution to the effective anisotropy in biocompatible iron oxide nanoparticles used for contrast agents, J Appl Phys, 97 (2005) $10 \mathrm{~J} 316$.

[31] V.B. Barbeta, R.F. Jardim, P.K. Kiyohara, F.B. Effenberger, L.M. Rossi, Magnetic properties of Fe3O4 nanoparticles coated with oleic anddodecanoic acids, J Appl Phys, 107 (2010) 073913.

[32] L. Gutiérrez, R. Mejías, D.F. Barber, S. Veintemillas-Verdaguer, C.J. Serna, F.J. Lázaro, M.P. Morales, AC magnetic susceptibility study of in vivo nanoparticle biodistribution, J Phys D: Appl Phys, 44 (2011) 255002.

[33] A.G. Roca, S. Veintemillas-Verdaguer, M. Port, C. Robic, C.J. Serna, M.P. Morales, Effect of nanoparticle and aggregate size on the relaxometric properties of MR contrast 
agents based on high quality magnetite nanoparticles, J Phys Chem B, 113 (2009) 70337039.

[34] S. Sun, H. Zeng, D.B. Robinson, S. Raoux, P.M. Rice, S.X. Wang, G. Li, Monodisperse MFe2O4 (M = Fe, Co, Mn) nanoparticles, J Am Chem Soc, 126 (2004) 273279.

[35] M. Mahmoudi, I. Lynch, M.R. Ejtehadi, M.P. Monopoli, F.B. Bombelli, S. Laurent, Protein-nanoparticle interactions: opportunities and challenges, Chem Rev, 111 (2011) 5610-5637.

[36] P. Rivera-Gil, D. Jimenez De Aberasturi, V. Wulf, B. Pelaz, P. Del Pino, Y. Zhao, J.M. De La Fuente, I. Ruiz De Larramendi, T. Rojo, X.J. Liang, W.J. Parak, The Challenge To Relate the Physicochemical Properties of Colloidal Nanoparticles to Their Cytotoxicity, Acc Chem Res, 3 (2012) 743-749.

[37] S.J. Soenen, M. De Cuyper, How to assess cytotoxicity of (iron oxide-based) nanoparticles: a technical note using cationic magnetoliposomes, Contrast Media Mol Imaging, 6 (2010) 153-164.

[38] F. Marano, S. Hussain, F. Rodrigues-Lima, A. Baeza-Squiban, S. Boland, Nanoparticles: molecular targets and cell signalling, Arch Toxicol, 85 (2011) 733-741.

[39] N.A. Monteiro-Riviere, A.O. Inman, L.W. Zhang, Limitations and relative utility of screening assays to assess engineered nanoparticle toxicity in a human cell line, Toxicol Appl Pharmacol, 234 (2009) 222-235.

[40] J. Gu, H. Xu, Y. Han, W. Dai, W. Hao, C. Wang, N. Gu, H. Xu, J. Cao, The internalization pathway, metabolic fate and biological effect of superparamagnetic iron oxide nanoparticles in the macrophage-like RAW264.7 cell, Sci China Life Sci, 54 (2011) 793-805.

[41] J. Asahi, H. Kamo, R. Baba, Y. Doi, A. Yamashita, D. Murakami, A. Hanada, T. Hirano, Bisphenol A induces endoplasmic reticulum stress-associated apoptosis in mouse non-parenchymal hepatocytes, Life Sci, 87 (2010) 431-438.

[42] A. Nel, T. Xia, L. Madler, N. Li, Toxic potential of materials at the nanolevel, Science, 311 (2006) 622-627.

[43] C. Harris, J.M. Hansen, Oxidative stress, thiols, and redox profiles, Methods Mol Biol, 889 (2012) 325-346.

[44] K. Jomova, M. Valko, Advances in metal-induced oxidative stress and human disease, Toxicology, 283 (2011) 65-87.

[45] H. Kamencic, A. Lyon, P.G. Paterson, B.H. Juurlink, Monochlorobimane fluorometric method to measure tissue glutathione, Anal Biochem, 286 (2000) 35-37.

[46] H.J. Eom, J. Choi, Oxidative stress of $\mathrm{CeO} 2$ nanoparticles via p38-Nrf-2 signaling pathway in human bronchial epithelial cell, Beas-2B, Toxicol Lett, 187 (2009) 77-83.

[47] M. Qi, E.A. Elion, MAP kinase pathways, J Cell Sci, 118 (2005) 3569-3572.

[48] D.R. Schultz, W.J. Harrington, Jr., Apoptosis: programmed cell death at a molecular level, Semin Arthritis Rheum, 32 (2003) 345-369.

[49] J.A. Kim, C. Aberg, A. Salvati, K.A. Dawson, Role of cell cycle on the cellular uptake and dilution of nanoparticles in a cell population, Nat Nanotechnol, 7 (2012) 62-68.

[50] L. Gutierrez, M. Vujic Spasic, M.U. Muckenthaler, F.J. Lazaro, Quantitative magnetic analysis reveals ferritin-like iron as the most predominant iron-containing species in the murine Hfe-haemochromatosis, Biochim Biophys Acta, 1822 (2012) 1147-1153. 
[51] A. Lopez, L. Gutierrez, F.J. Lazaro, The role of dipolar interaction in the quantitative determination of particulate magnetic carriers in biological tissues, Phys Med Biol, 52 (2007) 5043-5056.

[52] L.L. Estevanato, L.M. Lacava, L.C. Carvalho, R.B. Azevedo, O. Silva, F. Pelegrini, S.N. Bao, P.C. Morais, Z.G. Lacava, Long-term biodistribution and biocompatibility investigation of dextran-coated magnetite nanoparticle using mice as the animal model, J Biomed Nanotechnol, 8 (2012) 301-308.

[53] R.E. Mebius, G. Kraal, Structure and function of the spleen, Nat Rev Immunol, 5 (2005) 606-616.

[54] L. Gutiérrez, R. Mejías, F.J. Lázaro, C.J. Serna, D.F. Barber, M.P. Morales, Effect of anesthesia on magnetic nanoparticle biodistribution after intravenous injection, IEEE Trans Magn, 49 (2013).

[55] L. Gu, R.H. Fang, M.J. Sailor, J.H. Park, In vivo clearance and toxicity of monodisperse iron oxide nanocrystals, ACS Nano, 6 (2012) 4947-4954.

[56] M. Levy, N. Luciani, D. Alloyeau, D. Elgrabli, V. Deveaux, C. Pechoux, S. Chat, G. Wang, N. Vats, F. Gendron, C. Factor, S. Lotersztajn, A. Luciani, C. Wilhelm, F. Gazeau, Long term in vivo biotransformation of iron oxide nanoparticles, Biomaterials, 32 (2011) 3988-3999.

[57] G.D. LeSage, L.J. Kost, S.S. Barham, N.F. LaRusso, Biliary excretion of iron from hepatocyte lysosomes in the rat. A major excretory pathway in experimental iron overload, J Clin Invest, 77 (1986) 90-97.

[58] C. Mazzaccara, G. Labruna, G. Cito, M. Scarfo, M. De Felice, L. Pastore, L. Sacchetti, Age-Related Reference Intervals of the Main Biochemical and Hematological Parameters in C57BL/6J, 129SV/EV and C3H/HeJ Mouse Strains, PLoS One, 3 (2008) e3772.

[59] M.A. Schnell, C. Hardy, M. Hawley, K.J. Propert, J.M. Wilson, Effect of blood collection technique in mice on clinical pathology parameters, Hum Gene Ther, 13 (2002) 155-161. 